\title{
Relationship Between Red Blood Cell Distribution Width and All-Cause Mortality in Disseminated Intravascular Coagulation Patients: A Retrospective Analysis
}

Bin $\mathrm{Hu}^{\prime}$

Jinxia Cao'

Yangyang $\mathrm{Hu}^{2}$

Zuoan Qin ${ }^{3}$

Jun Wang'

'Department of Hematology, First People's Hospital of Changde City, Changde, Hunan, People's Republic of China; ${ }^{2}$ Department of Rheumatology and Immunology, Tongji Hospital, Tongji Medical College, Huazhong University of Science and Technology, Wuhan, Hubei, People's Republic of China; ${ }^{3}$ Department of Cardiovascular Medicine, First People's Hospital of Changde City, Changde, Hunan, People's Republic of China
Correspondence: Jun Wang Department of Hematology, First People's Hospital of Changde City, 8I8 Renmin Road, Wuling District, Changde, 415000, Hunan, People's Republic of China Tel +86-736-7788720

Email xueyeke2020@sina.com
Purpose: Studies regarding death risk factors of disseminated intravascular coagulation (DIC) patients were limited. We conducted this study to investigate whether red blood cell distribution width (RDW) was independently related to all-cause mortality of DIC patients. Methods: We used data from the Medical Information Mart for Intensive Care III version 1.4 (MIMIC-III v1.4). A total of 2098 patients with DIC were included. The main outcome was in-hospital all-cause mortality.

Results: After adjusting for potential covariates, the in-hospital all-cause mortality was positively correlated with RDW. The hazard ratio (HR), 95\% confidence intervals (CI), and $\mathrm{P}$-value were $1.08,(1.05,1.12)$, and $\mathrm{P}<0.0001$, respectively. The Kaplan-Meier curve found DIC patients with elevated RDW had a lower survival rate than patients with normal RDW $(\mathrm{P}<0.0001)$. A nonlinear relationship between RDW and mortality was found with the inflection point $19.2 \%$. When RDW $<19.2 \%$, RDW was positively correlated with in-hospital all-cause mortality of DIC patients (HR (95\% CI): 1.17 (1.11, 1.24), P<0.0001). An elevation in RDW greater than $19.2 \%$ did not result in an additional increased risk of mortality (HR=0.97, 95\% CI: 0.91-1.04, $\mathrm{P}=0.4617$ ).

Conclusion: RDW is an independent predictor of all-cause mortality in DIC patients. Furthermore, there is a nonlinear association between RDW and all-cause mortality of DIC patients.

Keywords: red blood cell distribution width, disseminated intravascular coagulation, mortality, MIMIC-III, retrospective study

\section{Introduction}

Disseminated intravascular coagulation (DIC) is a severe clinical syndrome characterized by widespread and uncontrolled activation of coagulation, which further leads to microvascular thrombosis, multiple organ dysfunction and severe bleeding tendency. ${ }^{1}$ DIC may result as a complication of serious infections, trauma, malignancies, liver diseases, and obstetric diseases. ${ }^{1}$ The occurrence of DIC is always accompanied by significantly increased mortality. ${ }^{2}$ Mortality risks have been shown to reach $20-50 \%$ in critically ill patients in the presence of DIC. ${ }^{2}$ Due to the poor prognosis of DIC, it is necessary to explore its associated risk factors for death. However, there are currently few clinical studies focusing on this field. 
The red blood cell (RBC) distribution width (RDW), a quantitative parameter, reflects the size variation of peripheral erythrocyte. ${ }^{3}$ RDW has been widely used to distinguish the etiology of anemia, including hemolytic anemia, thalassemia and iron deficiency anemia. ${ }^{4}$ Recently, based on the effects of inflammation on erythropoiesis, RDW is regarded as a marker related to inflammation. ${ }^{5}$ Several studies have reported that RDW was a potential parameter for predicting mortality in inflammation-related diseases, such as acute pancreatitis, ${ }^{6}$ sepsis, ${ }^{7}$ severe coronavirus disease 2019 (COVID-19), ${ }^{8}$ and acute myocardial infarction. ${ }^{9}$ There is ample evidence to demonstrate a wide-ranging crosstalk between DIC and inflammation. ${ }^{10}$ We speculated that RDW may be a potential death risk factor in patients with DIC. We conducted this study to evaluate whether the mortality of patients with DIC was independently affected by the RDW.

We used data from the Medical Information Mart for Intensive Care III version 1.4 (MIMIC-III v1.4), a publicly available database enrolling 46,476 patients in intensive care units (ICU) ${ }^{11}$ A total of 3044 patients with DIC were identified from the MIMIC-III. We have previously published a clinical study on mortality risk factors in patients with DIC using data of the MIMIC-III. ${ }^{12}$ The present study is the second report and focuses on the RDW.

\section{Methods}

\section{Data Sources}

The MIMIC-III database was approved by the Massachusetts Institute of Technology and the Institutional Review Boards of Beth Israel Deaconess Medical Center. ${ }^{11}$ The authors, Bin Hu and Zuoan Qin, obtained the access to the MIMIC-III (Record ID: 35942628 and 36208651).

\section{Data Extraction}

Structure Query Language (SQL) was designed to obtain related data from the database. The following information were collected: general information, causes of DIC, vital signs, scoring systems (the sequential organ failure assessment $\left(\mathrm{SOFA}^{13}\right)$ score, systemic inflammatory response syndrome $\left(\mathrm{SIRS}^{14}\right)$ score, and simplified acute physiology score II $\left(\right.$ SAPSII $\left.{ }^{15}\right)$ ), comorbidities, laboratory data and treatments. It should be noted that all the laboratory results extracted were the first test results after the patient entered the ICU. Primary endpoint was in-hospital all-cause mortality.

\section{Inclusion Criteria}

The diagnostic criteria for DIC were the scoring system recommended by Japanese Association of Acute Medicine (JAAM).${ }^{16}$ We calculated the patients' JAAM-DIC scores according to their SIRS scores, platelet, fibrin degradation products (FDP), and the international normalized ratio (INR). The diagnosis of DIC was established if JAAMDIC scores $\geq 4 .{ }^{16}$ The exclusion criteria were as follows:

-not first admission to the ICU;

-patients with unknown etiology of DIC;

-age $<14$ or $>89$ years old;

- stay in ICU of less than 24 hours;

-missing RDW data at ICU admission.

\section{Statistical Analysis}

We introduced univariate and multivariate Cox proportional-hazards regression model to evaluate the association between the exposure variable and outcome. Variables confirmed to have an impact on the outcome $(\mathrm{P}<0.05)$ by univariate analysis were used as covariates and were adjusted in the subsequent multivariate Cox proportional-hazards model. Other variables, which may affect RDW or outcome according to clinical experience and/or literature, were also introduced as covariates and adjusted. In addition, we used the log rank tests and Kaplan-Meier curve to compare the survival rates between DIC patients with normal RDW and elevated RDW. Regarding nonlinear correlation, we introduced smooth curve fitting. Subgroup analyses were performed using the stratified Cox proportional-hazards regression model. Sensitivity analysis was used to test the robustness of our results. We also converted RDW into a categorical variable, and calculated the P-value for trend in order to verify the results of RDW as the continuous variable. Modeling was performed using the statistical software package $\mathrm{R}$.

\section{Results}

\section{Patient Characteristics}

The detailed process of patient selection is shown in Figure 1. A total of 3044 patients satisfied the diagnostic criteria of DIC and of these, 2098 patients fulfilled the inclusion criteria for the study. Table 1 lists the baseline characteristics of the enrolled patients. The included 2098 patients were divided into the in-hospital survivors group $(\mathrm{n}=1529)$ and the non-survivors group $(\mathrm{n}=569)$. 


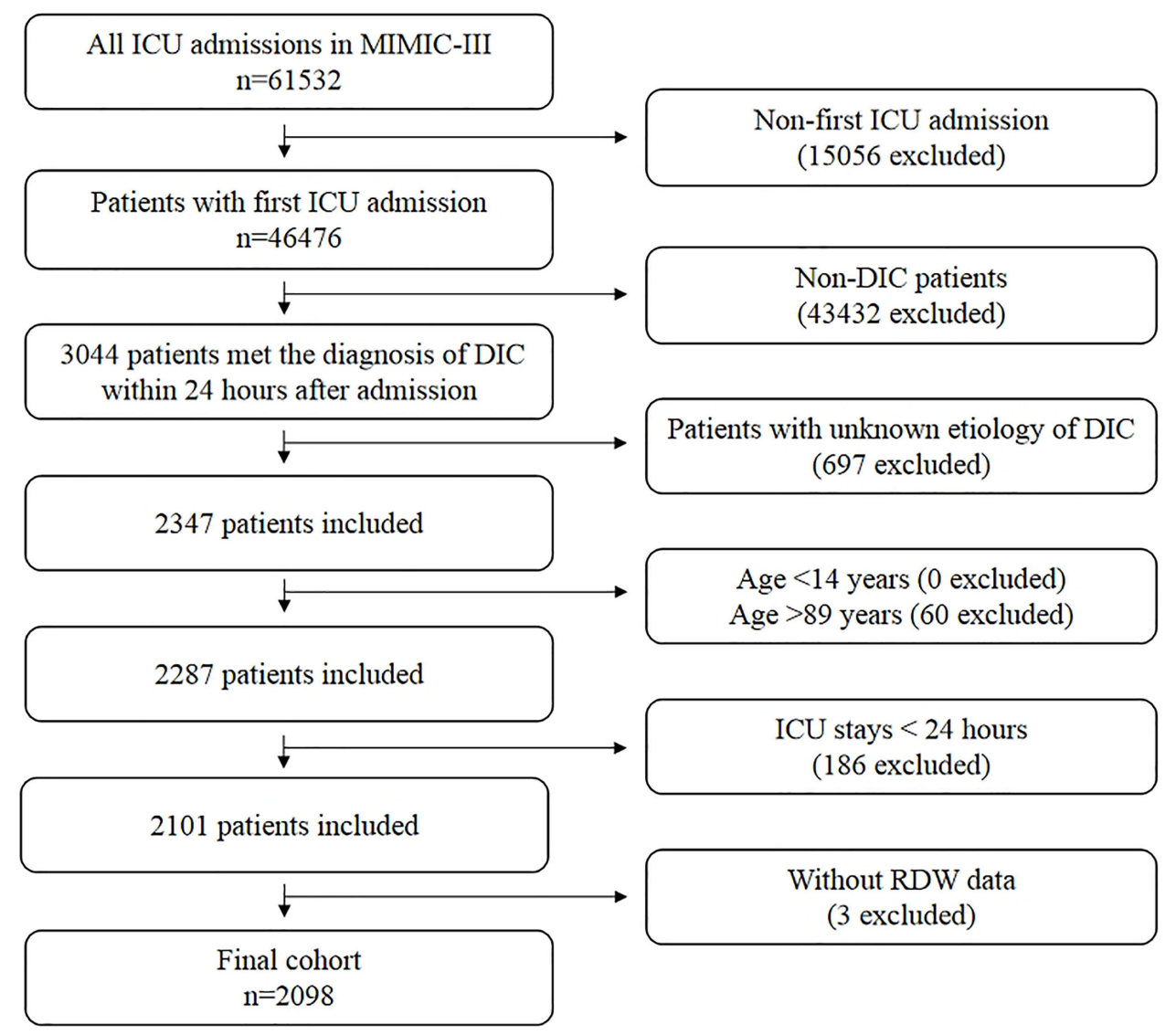

Figure I Flowchart of subject screening.

\section{The Association Between RDW and All-Cause Mortality}

Table 2 shows the results of the association analysis between RDW and all-cause mortality. Data are expressed as the hazard ratio (HR) and 95\% confidence interval (CI). We found that higher RDW was associated with an increased risk of in-hospital all-cause mortality (non-adjusted model: 1.11 (1.08, 1.14), $\mathrm{P}<0.0001$; minimally-adjusted model: 1.12 (1.09, 1.15), $\mathrm{P}<0.0001$; fully-adjusted model: 1.08 (1.05, 1.12), $\mathrm{P}<0.0001)$. A similar trend was found when the RDW was analyzed as a categorical variable (Table 2). Figure 2 shows the Kaplan-Meier curve for DIC patients with normal RDW and elevated RDW. DIC patients with elevated RDW had a lower survival rate than patients with normal RDW $(\mathrm{P}<0.0001)$.

\section{The Results of Nonlinear Relationship}

We demonstrated that there exists a nonlinear relationship between RDW and in-hospital all-cause mortality of DIC patients after adjusting for potential covariates (Figure 3). The inflection point was $19.2 \%$ according to the two- piecewise linear regression model (Table 3). When RDW $<19.2 \%$, RDW was positively correlated with in-hospital all-cause mortality of DIC patients (HR (95\% CI): 1.17 $(1.11,1.24), \mathrm{P}<0.0001)$. An elevation in RDW greater than $19.2 \%$ did not result in an additional increased risk of mortality (HR=0.97, 95\% CI: 0.91-1.04, $\mathrm{P}=0.4617)$.

\section{Subgroup Analyses}

Table 4 shows the subgroup analyses results. The interaction test was not statistically significant for sex, causes of DIC, congestive heart failure, hypertension, chronic obstructive pulmonary disease (COPD), diabetes, renal failure, liver diseases, use of continuous renal replacement therapy (CRRT), use of vasopressor drugs, use of mechanical ventilation, and hemoglobin $(\mathrm{P}$ for interaction $=$ $0.1537,0.2756,0.8724,0.7981,0.2661,0.0601,0.9512$, $0.1749,0.2058,0.9704,0.4614$, and 0.4309 ).

\section{Discussion}

This study focused on the association between RDW and DIC mortality. DIC is a critical illness that always results in short-term mortality. Moreover, RDW is a parameter 
Table I Baseline Characteristics of Participants

\begin{tabular}{|c|c|c|c|c|c|}
\hline Variables & Overall $(n=2098)$ & Survivors $(n=1529)$ & Non-Survivors $(n=569)$ & P-value & P-value* \\
\hline Age, mean (sd), years & $61.64(16.41)$ & $61.48(16.81)$ & $62.08(15.28)$ & 0.457 & 0.768 \\
\hline Weight, mean (sd), kg & $80.15(21.18)$ & $79.62(20.19)$ & $81.55(23.60)$ & 0.066 & 0.439 \\
\hline $\begin{array}{l}\text { Sex, } n(\%) \\
\text { Female } \\
\text { Male }\end{array}$ & $\begin{array}{l}898(42.80 \%) \\
1200(57.20 \%)\end{array}$ & $\begin{array}{l}669 \text { (43.75\%) } \\
860 \text { (56.25\%) }\end{array}$ & $\begin{array}{l}229(40.25 \%) \\
340(59.75 \%)\end{array}$ & 0.149 & - \\
\hline $\begin{array}{l}\text { Ethnicity, n(\%) } \\
\text { White } \\
\text { Black } \\
\text { Hispanic } \\
\text { Asian } \\
\text { Others }\end{array}$ & $\begin{array}{l}1432(68.26 \%) \\
135(6.43 \%) \\
79(3.77 \%) \\
68(3.24 \%) \\
384(18.30 \%)\end{array}$ & $\begin{array}{l}1052(68.80 \%) \\
97(6.34 \%) \\
66(4.32 \%) \\
58(3.79 \%) \\
256(16.74 \%)\end{array}$ & $\begin{array}{l}380(66.78 \%) \\
38(6.68 \%) \\
13(2.28 \%) \\
10(1.76 \%) \\
128(22.50 \%)\end{array}$ & 0.001 & - \\
\hline $\begin{array}{l}\text { Causes of DIC, n(\%) } \\
\text { Sepsis } \\
\text { Cardiovascular diseases } \\
\text { Trauma }\end{array}$ & $\begin{array}{l}1507(71.83 \%) \\
449(21.40 \%) \\
142(6.77 \%)\end{array}$ & $\begin{array}{l}1006(65.79 \%) \\
413(27.01 \%) \\
110(7.19 \%)\end{array}$ & $\begin{array}{l}50 \mathrm{I}(88.05 \%) \\
36(6.33 \%) \\
32(5.62 \%)\end{array}$ & $<0.001$ & - \\
\hline $\begin{array}{l}\text { Scoring systems, mean (sd) } \\
\text { SOFA } \\
\text { SAPSII } \\
\text { SIRS } \\
\text { JAAM-DIC }\end{array}$ & $\begin{array}{l}8.20(3.74) \\
44.51(15.75) \\
3.17(0.87) \\
4.95(0.93)\end{array}$ & $\begin{array}{l}7.31(3.22) \\
40.62(13.62) \\
3.11(0.89) \\
4.85(0.84)\end{array}$ & $\begin{array}{l}10.58(4.00) \\
54.95(16.34) \\
3.35(0.81) \\
5.21(1.08)\end{array}$ & $\begin{array}{l}<0.001 \\
<0.001 \\
<0.001 \\
<0.001\end{array}$ & $\begin{array}{l}<0.001 \\
<0.001 \\
<0.001 \\
<0.001\end{array}$ \\
\hline $\begin{array}{l}\text { Comorbidities, } \mathrm{n}(\%) \\
\text { Congestive heart failure } \\
\text { Hypertension } \\
\text { COPD } \\
\text { Diabetes } \\
\text { Renal failure } \\
\text { Liver diseases }\end{array}$ & $\begin{array}{l}519(24.74 \%) \\
919(43.80 \%) \\
325(15.49 \%) \\
452(21.54 \%) \\
282(13.44 \%) \\
677(32.27 \%)\end{array}$ & $\begin{array}{l}382(25.00 \%) \\
704(46.04 \%) \\
242(15.84 \%) \\
338(22.11 \%) \\
197(12.89 \%) \\
407(26.64 \%)\end{array}$ & $\begin{array}{l}137(24.08 \%) \\
215(37.79 \%) \\
83(14.59 \%) \\
114(20.04 \%) \\
85(14.94 \%) \\
270(47.45 \%)\end{array}$ & $\begin{array}{l}0.663 \\
<0.001 \\
0.482 \\
0.305 \\
0.222 \\
<0.001\end{array}$ & $\begin{array}{l}- \\
- \\
- \\
- \\
- \\
-\end{array}$ \\
\hline MBP, mean (sd), mmHg & $76.32(10.60)$ & $77.19(10.31)$ & $73.96(11.02)$ & $<0.001$ & $<0.001$ \\
\hline Temperature, mean (sd), ${ }^{\circ} \mathrm{C}$ & $36.86(0.76)$ & $36.92(0.69)$ & $36.70(0.89)$ & $<0.001$ & $<0.001$ \\
\hline $\mathrm{SPO}$, mean (sd), \% & $97.09(3.40)$ & $97.54(2.18)$ & $95.88(5.29)$ & $<0.001$ & $<0.001$ \\
\hline $\begin{array}{l}\text { Laboratory parameters, mean (sd) } \\
\text { Hemoglobin, g/dL } \\
\text { Hematocrit, \% } \\
\text { RBC, } 10^{9} / \mathrm{L} \\
\text { MCV, fl } \\
\text { Platelet, } 10^{9} / \mathrm{L} \\
\text { WBC, } 10^{9} / \mathrm{L} \\
\text { APTT, seconds } \\
\text { PT, seconds } \\
\text { PT - INR } \\
\text { Creatinine, } \mathrm{mEq} / \mathrm{L} \\
\text { Urea nitrogen, } \mathrm{mg} / \mathrm{dL} \\
\text { Glucose, } \mathrm{mg} / \mathrm{dL} \\
\text { Potassium, } \mathrm{mmol} / \mathrm{L} \\
\text { Sodium, mmol/L } \\
\text { Bicarbonate, } \mathrm{mg} / \mathrm{dL} \\
\text { Anion gap, } \mathrm{mEg} / \mathrm{L}\end{array}$ & $\begin{array}{l}9.90(2.21) \\
29.22(6.60) \\
3.20(0.76) \\
91.53(7.94) \\
102.85(106.18) \\
11.85(15.76) \\
47.00(27.10) \\
18.19(7.55) \\
1.87(1.82) \\
1.58(1.60) \\
31.09(25.92) \\
151.65(76.47) \\
4.19(0.86) \\
137.56(5.52) \\
21.01(4.96) \\
15.18(5.23)\end{array}$ & $\begin{array}{l}9.95(2.16) \\
29.30(6.45) \\
3.22(0.74) \\
90.69(7.34) \\
106.68(113.40) \\
11.46(14.90) \\
45.25(24.90) \\
17.52(6.98) \\
1.78(1.98) \\
1.47(1.62) \\
27.34(23.29) \\
152.15(75.79) \\
4.17(0.87) \\
137.48(5.20) \\
21.58(4.50) \\
14.31(4.58)\end{array}$ & $\begin{array}{l}9.77(2.33) \\
28.99(6.98) \\
3.14(0.80) \\
93.79(8.98) \\
92.57(83.00) \\
12.90(17.86) \\
51.67(31.79) \\
19.99(8.66) \\
2.12(1.27) \\
1.89(1.49) \\
41.17(29.68) \\
150.30(78.33) \\
4.26(0.84) \\
137.76(6.30) \\
19.47(5.76) \\
17.47(6.07)\end{array}$ & $\begin{array}{l}0.106 \\
0.337 \\
0.035 \\
<0.001 \\
0.007 \\
0.063 \\
<0.001 \\
<0.001 \\
<0.001 \\
<0.001 \\
<0.001 \\
0.622 \\
0.033 \\
0.309 \\
<0.001 \\
<0.001\end{array}$ & $\begin{array}{l}0.117 \\
0.239 \\
0.032 \\
<0.001 \\
<0.001 \\
0.620 \\
<0.001 \\
<0.001 \\
<0.001 \\
<0.001 \\
<0.001 \\
0.100 \\
0.008 \\
0.187 \\
<0.001 \\
<0.001\end{array}$ \\
\hline
\end{tabular}

(Continued) 
Table I (Continued).

\begin{tabular}{|c|c|c|c|c|c|}
\hline Variables & Overall $(n=2098)$ & Survivors $(n=1529)$ & Non-Survivors $(n=569)$ & P-value & P-value* \\
\hline \multicolumn{6}{|l|}{ Treatments, n (\%) } \\
\hline Use of CRRT & 210 (10.01\%) & 85 (5.56\%) & 125 (21.97\%) & $<0.001$ & - \\
\hline Use of vasopressor drugs & $1248(59.49 \%)$ & $830(54.28 \%)$ & 418 (73.46\%) & $<0.001$ & - \\
\hline Use of mechanical ventilation & $1508(71.88 \%)$ & $1062(69.46 \%)$ & 446 (78.38\%) & $<0.001$ & - \\
\hline RDW, mean (sd), \% & $16.00(2.68)$ & $15.56(2.40)$ & $17.19(3.01)$ & $<0.001$ & $<0.001$ \\
\hline RDW (dichotomous), n (\%) & & & & $<0.001$ & - \\
\hline Normal ( $\leq 15.5 \%)$ & $1170(55.77 \%)$ & $960(62.79 \%)$ & $210(36.91 \%)$ & & \\
\hline Elevated (>15.5\%) & $928(44.23 \%)$ & $569(37.21 \%)$ & 359 (63.09\%) & & \\
\hline RDW (quartiles), n (\%) & & & & $<0.001$ & - \\
\hline $11.80-14.00 \%$ & $508(24.21 \%)$ & $434(28.38 \%)$ & 74 (13.01\%) & & \\
\hline $14.10-15.10 \%$ & $518(24.69 \%)$ & $415(27.14 \%)$ & $103(18.10 \%)$ & & \\
\hline $15.20-17.30 \%$ & $544(25.93 \%)$ & $385(25.18 \%)$ & 159 (27.94\%) & & \\
\hline $17.40-29.10 \%$ & $528(25.17 \%)$ & 295 (19.29\%) & $233(40.95 \%)$ & & \\
\hline
\end{tabular}

Note: $P^{*}$ indicated $U$-test.

Abbreviations: DIC, disseminated intravascular coagulation; SOFA, sequential organ failure assessment; SAPSII, simplified acute physiology score II; SIRS, systemic inflammatory response syndrome; JAAM, Japanese Association of Acute Medicine; COPD, chronic obstructive pulmonary disease; MBP, mean blood pressure; RBC, red blood cell; MCV, mean corpuscular volume; WBC, white blood cell; APTT, activated partial thromboplastin time; PT, prothrombin time; INR, international normalized ratio; CRRT, continuous renal replacement therapy; RDW, red blood cell distribution width.

Table 2 Univariate and Multivariate Results by Cox Regression

\begin{tabular}{|c|c|c|c|}
\hline Exposure & $\begin{array}{l}\text { Non-Adjusted Model HR, } \\
95 \% \mathrm{CI}, \mathrm{P}\end{array}$ & $\begin{array}{l}\text { Minimally-Adjusted Model HR, } \\
95 \% \mathrm{CI}, \mathrm{P}\end{array}$ & $\begin{array}{l}\text { Fully-Adjusted Model HR, } \\
95 \% \mathrm{Cl}, \mathrm{P}\end{array}$ \\
\hline RDW (continuous) & $1.11(1.08,1.14)<0.0001$ & $1.12(1.09,1.15)<0.0001$ & $1.08(1.05,1.12)<0.0001$ \\
\hline \multicolumn{4}{|l|}{ RDW (dichotomous) } \\
\hline Normal ( $\leq 15.5 \%)$ & I.0 (Ref) & I.0 (Ref) & I.0 (Ref) \\
\hline Elevated(>15.5\%) & $\mathrm{I} .87(\mathrm{I} .57,2.2 \mathrm{I})<0.000 \mathrm{I}$ & $1.91(1.61,2.27)<0.0001$ & $1.66(1.36,2.03)<0.0001$ \\
\hline \multicolumn{4}{|l|}{ RDW (quartiles) } \\
\hline QI (1I.80-14.00\%) & I.0 (Ref) & I.0 (Ref) & I.0 (Ref) \\
\hline Q2 (14.10-15.10\%) & $1.12(0.83,1.52) 0.4428$ & $1.07(0.80,1.45) 0.6425$ & $0.91(0.66,1.25) 0.5536$ \\
\hline Q3 (I5.20-17.30\%) & $1.63(1.23,2.14) 0.0006$ & $1.56(1.18,2.06) 0.0016$ & $1.30(0.95,1.76) 0.0982$ \\
\hline Q4 (17.40-29.10\%) & $2.38(1.83,3.10)<0.0001$ & $2.42(1.86,3.15)<0.0001$ & $1.96(1.43,2.69)<0.0001$ \\
\hline$P$ for trend & $1.37(1.27,1.49)<0.0001$ & $1.39(1.28,1.51)<0.0001$ & $1.32(1.19,1.46)<0.0001$ \\
\hline
\end{tabular}

Notes: Non-adjusted model: no covariates was adjusted for. Minimally-adjusted model: we only adjusted for age and sex. Fully-adjusted model: we adjusted for age, sex, ethnicity, care unit, causes of DIC, SOFA score, JAAM-DIC score, liver diseases, use of CRRT, use of vasopressor drugs, use of mechanical ventilation, hemoglobin, RBC, MCV, APTT, bicarbonate, urea nitrogen, anion gap, and potassium.

Abbreviations: $\mathrm{HR}$, hazard ratio; $\mathrm{Cl}$, confidence interval; Ref, reference.

that changes relatively rapidly during the course of a disease and may have little impact on long-term mortality. Hence, in this study we only introduced in-hospital mortality, which is a short-term outcome, as our main outcome. We showed that all-cause mortality in DIC patients was positively correlated with the level of RDW, and demonstrated that RDW is an independently correlated death risk factor in DIC patients. More importantly, we also observed a nonlinear correlation. The linear increase between RDW and mortality reached a peak at an RDW of
$19.2 \%$, and an elevation in RDW above this value did not result in additional increased mortality. The results of our study may contribute to identifying high-risk DIC patients in early stages of the disease. Early identification of these high-risk patients means early intervention, which may improve the prognosis of DIC patients.

Several studies have reported a close association among DIC, inflammation, and RDW. ${ }^{5,17,18}$ The systemic inflammatory response is known to be an important initiating factor in the development of DIC. ${ }^{10}$ In the inflammatory 


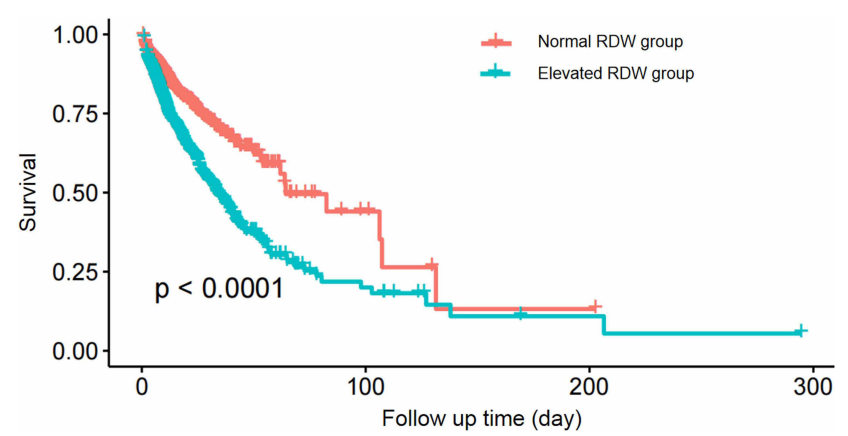

Figure 2 The K-M survival curve of normal RDW ( $\leq 15.5 \%)$ group and elevated RDW (>15.5\%) group.

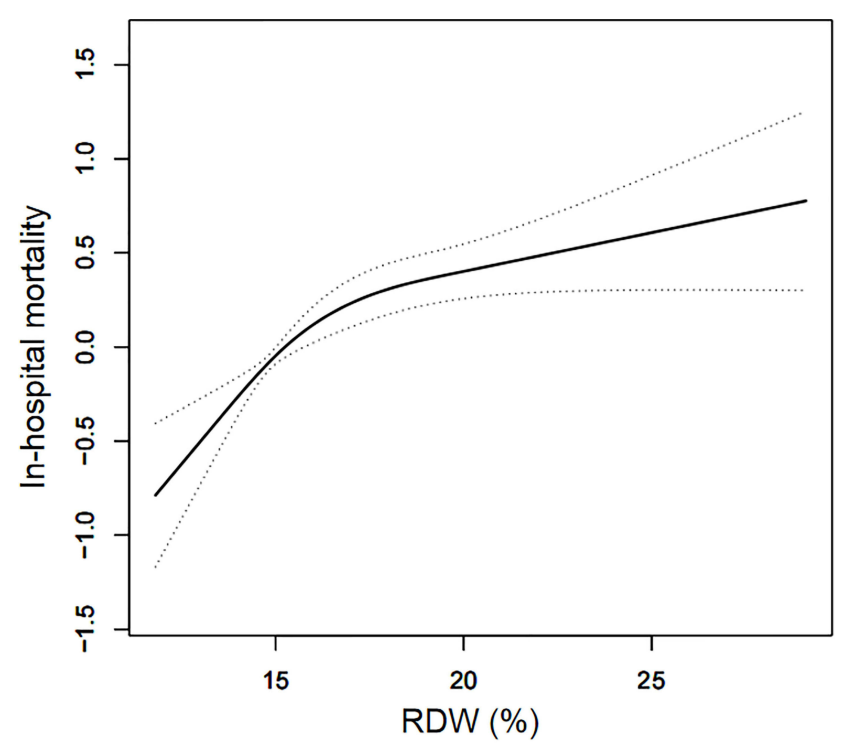

Figure 3 Nonlinear relationship between RDW and in-hospital all-cause mortality of DIC patients.

response, a large amount of pro-inflammatory cytokines and tissue factor, are released by mononuclear cells. The tissue factor/factor VII pathway is known as the principal initiator of thrombin generation in the early stage of DIC. ${ }^{10}$ Proinflammatory cytokines may further injure the endothelial cells and interfere with endothelial-related anticoagulant activity, which will lead to more severe and widespread activation of blood coagulation. ${ }^{18}$ Excessive proinflammatory cytokines may also result in erythrocyte dysfunction, including abnormal erythropoiesis, increased erythrocyte destruction, and shortened erythrocyte life span, leading to increased RDW. ${ }^{5}$ RDW was demonstrated to have a positive relationship with the C-reactive protein (CRP) and the erythrocyte sedimentation rate (ESR), which are the important inflammatory-related parameters. ${ }^{19}$ Moreover, microvascular thrombosis is a prominent feature of DIC. When DIC occur, microvascular thrombosis forms a network in the microvessel. ${ }^{20,21}$ $\mathrm{RBC}$ can be mechanically damaged and rupture as they pass through this thrombosis network. ${ }^{20,21}$ This process is called microangiopathic hemolytic anemia (MHA). ${ }^{21}$ MHA can lead to increased destruction of erythrocyte, compensatory hyperplasia of erythrocyte, and abnormal erythropoiesis, which further results in an abnormal RDW. The close pathophysiological association among DIC and RDW may explain why elevated RDW is associated with all-cause mortality of DIC patients.

Subgroup analysis is important for in-depth scientific study. ${ }^{22}$ Herein, we conducted detailed subgroup analyses using sex, causes of DIC, congestive heart failure, hypertension, $\mathrm{COPD}$, diabetes, renal failure, liver diseases, use of CRRT, use of vasopressor drugs, use of mechanical ventilation, and hemoglobin as stratification variables. Interaction test was not statistically significant, which meant that the positive association between RDW and mortality in patients with DIC was stable.

Regarding the selection of covariates, we first applied the univariate Cox proportional-hazards model to evaluate the association between variables and patient outcome (Supplementary Table 1). Variables confirmed to have an impact on patient outcome $(\mathrm{P}<0.05)$ by univariate analysis

Table 3 Nonlinearity Addressing of RDW and In-Hospital All-Cause Mortality

\begin{tabular}{|c|c|}
\hline Exposure & $\mathrm{HR}, 95 \% \mathrm{CI}, \mathrm{P}$ value \\
\hline Fitting model by standard Cox proportional-hazards regression model & $1.08(1.05,1.12)<0.0001$ \\
\hline \multicolumn{2}{|l|}{ Fitting model using two-piecewise Cox proportional-hazards regression model } \\
\hline Inflection point & $19.2 \%$ \\
\hline$<19.2 \%$ & $1.17(1.11,1.24)<0.0001$ \\
\hline$\geq 19.2 \%$ & $0.97(0.91,1.04) 0.4617^{*}$ \\
\hline$P$ for log-likelihood ratio test & $<0.001$ \\
\hline
\end{tabular}

Notes: *The results indicated that there was a saturation effect on the relationship between RDW and mortality of DIC patients. The linear increase between RDW and mortality reached a peak at a RDW of $19.2 \%$. An elevation in RDW greater than $19.2 \%$ did not result in an additional increased risk of mortality. But, DIC patients with RDW $\geq 19.2 \%$ still had a higher mortality than patients with RDW $<19.2 \%$. 
Table 4 Subgroup Analysis of the Relationship Between RDW and In-Hospital All-Cause Mortality

\begin{tabular}{|c|c|c|c|c|}
\hline Characteristic & Number of Patients & HR (95\% Cl) & $P$ value & P for Interaction \\
\hline Sex & & & & 0.1537 \\
\hline Female & 873 & $1.12(1.06,1.17)$ & $<0.0001$ & \\
\hline Male & 1155 & $1.07(1.02,1.11)$ & 0.0015 & \\
\hline Causes of DIC & & & & 0.2756 \\
\hline Sepsis & 1464 & $1.09(1.05,1.12)$ & $<0.000$ I & \\
\hline Cardiovascular diseases & 432 & 1.18 (1.01, I.39) & 0.0421 & \\
\hline Trauma & 141 & $1.26(1.01,1.59)$ & 0.0443 & \\
\hline Congestive heart failure & & & & 0.8724 \\
\hline No & 1519 & $1.09(1.05,1.13)$ & $<0.0001$ & \\
\hline Yes & 509 & $1.09(1.03,1.16)$ & 0.0033 & \\
\hline Hypertension & & & & $0.798 \mid$ \\
\hline No & 1142 & $1.07(1.03,1.11)$ & 0.0006 & \\
\hline Yes & 886 & $1.06(1.01,1.12)$ & 0.0166 & \\
\hline COPD & & & & $0.266 I$ \\
\hline No & 1707 & $1.09(1.06,1.13)$ & $<0.0001$ & \\
\hline Yes & 321 & $1.04(0.95,1.13)$ & 0.4276 & \\
\hline Diabetes & & & & 0.0601 \\
\hline No & 1590 & $1.06(1.02,1.09)$ & 0.0025 & \\
\hline Yes & 438 & $1.13(1.06,1.20)$ & 0.0001 & \\
\hline Renal failure & & & & 0.9512 \\
\hline No & 1754 & $1.07(1.03,1.10)$ & 0.0001 & \\
\hline Yes & 274 & $1.07(0.98,1.16)$ & 0.1427 & \\
\hline Liver diseases & & & & 0.1749 \\
\hline No & 1355 & $1.09(1.04,1.14)$ & $<0.0001$ & \\
\hline Yes & 673 & $1.05(1.00,1.09)$ & 0.0359 & \\
\hline Use of CRRT & & & & 0.2058 \\
\hline No & 1822 & $1.10(1.06,1.14)$ & $<0.0001$ & \\
\hline Yes & 206 & $1.04(0.96,1.12)$ & 0.3019 & \\
\hline Use of vasopressor drugs & & & & 0.9704 \\
\hline No & 813 & $1.08(1.02,1.14)$ & 0.0050 & \\
\hline Yes & 1215 & $1.08(1.05,1.12)$ & $<0.0001$ & \\
\hline Use of mechanical ventilation & & & & 0.4614 \\
\hline No & 558 & $1.10(1.04,1.18)$ & 0.0015 & \\
\hline Yes & 1470 & $1.08(1.04,1.11)$ & $<0.000$ I & \\
\hline Hemoglobin & & & & 0.4309 \\
\hline$<8 \mathrm{~g} / \mathrm{dL}$ & 373 & $1.11(1.04,1.18)$ & 0.0016 & \\
\hline$\geq 8 \mathrm{~g} / \mathrm{dL}$ & 1655 & $1.08(1.04,1.11)$ & $<0.0001$ & \\
\hline
\end{tabular}

Abbreviations: DIC, disseminated intravascular coagulation; COPD, chronic obstructive pulmonary disease; CRRT, continuous renal replacement therapy.

were further introduced as covariates and adjusted in the subsequent multivariate analysis. The JAAM-DIC score already includes the SIRS score. SOFA score and SAPSII score contains some of the same elements. Hence, we only introduced the JAAM-DIC score and the SOFA score as covariates. In addition, mean blood pressure (MBP), SPO2 and creatinine are already included in the SOFA score and were not used as covariates. Some variables, which had no significant impact on patient outcome according to univariate analysis but may affect the RDW (including RBC, hemoglobin, and MCV), were also introduced as covariates and adjusted. 
It should be noted that, with respect to the diagnosis of DIC, there are three main criteria recommended by different associations, including the Scientific and Standardization Committee (SSC)/International Society of Thrombosis and Haemostasis (ISTH), the JAAM, and the Japanese Ministry of Health, Labour and Welfare (JMHLW). ${ }^{23}$ A previous study compared the different diagnostic criteria and found that the JAAM scoring system was the most sensitive. ${ }^{24}$ Thus, we introduced the JAAM scoring system in this study. However, despite the fact that JAAM scoring system had a high sensitivity, its specificity was relatively low and was useful mainly for patients with sepsis. ${ }^{25}$ Thus, we may have enrolled nonDIC patients in our study.

In 2015 , Kury et $\mathrm{al}^{26}$ reproduced, as a retrospective study using the data from MIMIC-II, a large clinical study: ${ }^{27}$ by the JAAM, about DIC, in the journal Critical Care (PMID: 23787004). They identified 2257 related patients and found their results were nearly consistent with the original study. This further demonstrated that the results drawn from a retrospective study regarding DIC in MIMIC database were reliable.

Our work has a number of strengths. First, this study enrolled 2098 patients, which is a very large sample size for the clinical study of DIC. Second, we explored both of the linear and nonlinear relationship. Third, we analyzed the exposure variable (RDW) as not only a continuous variable but also a categorical variable. We calculated the hazard ratio using binary logistic regression models. Such a method can minimize the incidence of contingency in statistical analysis, enhance the reliability of the final results.

There are some limitations to our study. First, some variables, including FDP, D-dimer, CRP, lactate, $\mathrm{pH}$, thrombin, antithrombin, procalcitonin, and severity of the causes of DIC, may also be related to the prognosis of patients with DIC. However, due to a high percentage of missing data or inability to obtain these variables, we were unable to include them in our data analyses. Second, in terms of treatment, we only analyzed CRRT, mechanical ventilation and vasopressor. The prognosis of DIC patients may also be influenced by other therapeutic measures, such as plasma transfusion, cryoprecipitation transfusion, and platelet transfusion; however, we could not obtain these data from the MIMIC-III database. Third, our study was a retrospective study based on a public clinical database and we did not have an established protocol before this study started.

\section{Conclusion}

RDW is an independent predictor of all-cause mortality in DIC patients. Furthermore, there is a nonlinear association between RDW and all-cause mortality of DIC patients.

\section{Data Sharing Statement}

The datasets are publicly available in the https://mimic. physionet.org/.

\section{Funding}

This study was supported by grants from the Clinical Medical Technology Innovation Guide Project of Hunan (NO.2017SK51305).

\section{Disclosure}

The authors declare that they have no competing interests.

\section{References}

1. Gando S, Levi M, Toh CH. Disseminated intravascular coagulation. Nat Rev Dis Primers. 2016;2:16037. doi:10.1038/nrdp.2016.37

2. Papageorgiou C, Jourdi G, Adjambri E, et al. Disseminated intravascular coagulation: an update on pathogenesis, diagnosis, and therapeutic strategies. Clin Appl Thrombosis/Hemostasis. 2018;24 (9_suppl):8s-28s. doi:10.1177/1076029618806424

3. May JE, Marques MB, Reddy VVB, Gangaraju R. Three neglected numbers in the CBC: the RDW, MPV, and NRBC count. Cleve Clin $J$ Med. 2019;86(3):167-172. doi:10.3949/ccjm.86a.18072

4. Lin CK, Lin JS, Chen SY, Jiang ML, Chiu CF. Comparison of hemoglobin and red blood cell distribution width in the differential diagnosis of microcytic anemia. Arch Pathol Lab Med. 1992;116 (10):1030-1032.

5. Salvagno GL, Sanchis-Gomar F, Picanza A, Lippi G. Red blood cell distribution width: a simple parameter with multiple clinical applications. Crit Rev Clin Lab Sci. 2015;52(2):86-105. doi:10.3109/10408363.2014.992064

6. Zhang FX, Li ZL, Zhang ZD, Ma XC. Prognostic value of red blood cell distribution width for severe acute pancreatitis. World $j$ Gastroenterol. 2019;25(32):4739-4748. doi:10.3748/wjg.v25. i32.4739

7. Hu ZD, Lippi G, Montagnana M. Diagnostic and prognostic value of red blood cell distribution width in sepsis: a narrative review. Clin Biochem. 2020;77:1-6. doi:10.1016/j.clinbiochem.2020.01.001

8. Wang C, Zhang H, Cao X, et al. Red cell distribution width (RDW): a prognostic indicator of severe COVID-19. Ann Transl Med. 2020;8 (19):1230. doi:10.21037/atm-20-6090

9. Uyarel H, Ergelen M, Cicek G, et al. Red cell distribution width as a novel prognostic marker in patients undergoing primary angioplasty for acute myocardial infarction. Coron Artery Dis. 2011;22 (3):138-144. doi:10.1097/MCA.0b013e328342c77b

10. Levi M, van der Poll T. Coagulation and sepsis. Thromb Res. 2017;149:38-44. doi:10.1016/j.thromres.2016.11.007

11. Johnson AE, Pollard TJ, Shen L, et al. MIMIC-III, a freely accessible critical care database. Sci Data. 2016;3:160035.

12. Hu B, Cao J, Hu Y, Qin Z, Wang J. The association between serum anion gap and all-cause mortality in disseminated intravascular coagulation patients: a retrospective analysis. Int $J$ Gen Med. 2021;14:4535-4544. doi:10.2147/IJGM.S318334 
13. Lambden S, Laterre PF, Levy MM, Francois B. The SOFA score-development, utility and challenges of accurate assessment in clinical trials. Crit Care. 2019;23(1):374.

14. Jacome T, Tatum D. Systemic Inflammatory Response Syndrome (SIRS) score independently predicts poor outcome in isolated traumatic brain injury. Neurocritical Care. 2018;28(1):110-116.

15. Capuzzo M, Moreno RP, Le Gall JR. Outcome prediction in critical care: the simplified acute physiology score models. Curr Opin Crit Care. 2008;14(5):485-490. doi:10.1097/MCC.0b013e32830864d7

16. Gando S, Iba T, Eguchi Y, et al. A multicenter, prospective validation of disseminated intravascular coagulation diagnostic criteria for critically ill patients: comparing current criteria. Crit Care Med. 2006;34(3):625-631. doi:10.1097/01.CCM.0000202209.42491.38

17. Iba T, Levi M, Levy JH. Sepsis-induced coagulopathy and disseminated intravascular coagulation. Semin Thromb Hemost. 2020;46 (1):89-95.

18. Levi M, Poll T. Coagulation in patients with severe sepsis. Semin Thromb Hemost. 2015;41(1):9-15. doi:10.1055/s-0034-1398376

19. Lippi G, Targher G, Montagnana M, Salvagno GL, Zoppini G, Guidi GC. Relation between red blood cell distribution width and inflammatory biomarkers in a large cohort of unselected outpatients. Arch Pathol Lab Med. 2009;133(4):628-632. doi:10.5858/133.4.628

20. Kurosawa S, Stearns-Kurosawa DJ. Complement, thrombotic microangiopathy and disseminated intravascular coagulation. $J$ Intensive Care. 2014;2(1):65. doi:10.1186/s40560-014-0061-4
21. Wada H, Matsumoto T, Suzuki K, et al. Differences and similarities between disseminated intravascular coagulation and thrombotic microangiopathy. Thromb J. 2018;16:14. doi:10.1186/s12959-0180168-2

22. Vandenbroucke JP, von Elm E, Altman DG, et al. Strengthening the Reporting of Observational Studies in Epidemiology (STROBE): explanation and elaboration. PLoS Med. 2007;4(10):e297. doi:10.1371/journal.pmed.0040297

23. Wada H, Matsumoto T, Yamashita Y. Diagnosis and treatment of disseminated intravascular coagulation (DIC) according to four DIC guidelines. J Intensive Care. 2014;2(1):15. doi:10.1186/2052-0492-2-15

24. Kury FS, Cimino JJ. Computationally comparing and analyzing all published scoring systems for diagnosis of disseminated intravascular coagulation. Stud Health Technol Inform. 2015;216:956.

25. Gando S, Wada H, Asakura H, et al. Evaluation of new Japanese diagnostic criteria for disseminated intravascular coagulation in critically ill patients. Clin Appl Thrombosis/Hemostasis. 2005;11 (1):71-76. doi:10.1177/107602960501100108

26. Kury FS, Huser V, Cimino JJ. Reproducing a prospective clinical study as a computational retrospective study in MIMIC-II. AMIA Annu Symp Proc. 2015;2015:804-813.

27. Gando S, Saitoh D, Ogura H, et al. A multicenter, prospective validation study of the Japanese Association for Acute Medicine disseminated intravascular coagulation scoring system in patients with severe sepsis. Crit Care. 2013;17(3):R111. doi:10.1186/cc12783
International Journal of General Medicine

\section{Publish your work in this journal}

The International Journal of General Medicine is an international, peer-reviewed open-access journal that focuses on general and internal medicine, pathogenesis, epidemiology, diagnosis, monitoring and treatment protocols. The journal is characterized by the rapid reporting of reviews, original research and clinical studies

\section{Dovepress}

across all disease areas. The manuscript management system is completely online and includes a very quick and fair peer-review system, which is all easy to use. Visit http://www.dovepress.com/ testimonials.php to read real quotes from published authors. 